\title{
ANFIS based Transformerless UPFC for Effective Power Flow Control
}

\author{
Kongathi Sivaram ${ }^{1}$ | P Ankineedu Prasad ${ }^{2}$ \\ 1PG Student, Dept of EEE, Vikas College of Engineering, Vijayawada, India \\ ${ }^{2}$ Associate Professor\& HOD, Dept of EEE, Vikas College of Engineering, Vijayawada, India
}

To Cite this Article

Kongathi Sivaram and P Ankineedu Prasad, "ANFIS based Transformerless UPFC for Effective Power Flow Control", International Journal for Modern Trends in Science and Technology, Vol. 06, Issue 07, July 2020, pp.:148-152; https://doi.org/10.46501/IJMTST060724

\section{Article Info}

Received on 17-June-2020, Revised on 28-June-2020, Accepted on 15-July-2020, Published on 22-July-2020.

\section{ABSTRACT}

This paper focus on specially designed ANFIS based Power Quality Conditioner for Micro Grid applications. Three leg inverter coupled with solar PV with MPPT used as Compensator can be used for distinct DGs in the micro grid for power quality improvement of the entire system. Optimum control can be achieved to avoid detraction for voltage, current and Power flowing between Grid and DG. The Power Quality conditioner and DG inverter have dual use for this particular purpose. Primarily used as power converter for injecting power created from DG to Grid, secondly performed as parallel Active Power Filter for compensating harmonics, unbalanced voltage, current, active and reactive power demand for the balance and unbalance burden with in the Grid and neutral conductors. This paper is extended with ANFIS Controller for better improvement of Power Quality. The above mentioned task extensively simulated under MATLAB/Simulink platform revels that soon after compensation the THD.

KEY WORDS: Transformerless UPFC, CMI Converters, Power Quality, ANFIS Controller, PI Controller and Total Harmonic Distortion.

Copyright (C) 2020 International Journal for Modern Trends in Science and Technology

DOI: https://doi.org/10.46501/IJMTST060724

\section{INTRODUCTION}

Nowadays, power quality related issues are most common problems in the era of electrical systems. This is because of wide utilization of advanced controlling elements such as, information technological equipments, PLC-SCADA, and advanced power electronics devices such as ASD-Drives, leads to changes the nature of electric loads and causes the power quality issues. Due to non-linearity nature in these loads cause disturbances in voltage and current profiles. The increased sensitivity of the vast majority of processes (industrial, services and even residential) to PQ problems turns the availability of electric power with quality a crucial factor for competitiveness in every activity sector. The most critical areas are the continuous process industry and the information technology services. Electrical devices may fail permeant, may malfunction, or not to operate because of proper flow of electrical power. There are many reasons causes for poor power quality, but the most common problems in the electrical are: Voltage Spikes/Dips, frequency variations, blackouts, electrical line noise, harmonic distortion and voltage sag/swell.

The progression in power electronics innovation has capacitated the utilization of voltage source inverters (VSI) and current source inverters (CSI) at both the transmission and 
circulation levels. A bunch blend of VSI and CSI based systems prompt such huge numbers of transformative devices, for example, Unified Power Flow Conditioner (UPFC), Static Synchronous Compensator (STATCOM), and Dynamic Voltage Restorer (DVR), which made FACTS devices more noticeable. Viable usages of these FACTS devices for voltage control, power stream control and security concerns have been represented in the artistic works [1-3]. As a case, DVR is used to upgrade power quality. The majority of the perils remain for touchy gear in power lattices which emerge because of voltage hangs and swells. UPFC and synchronous static STATCOM, are used to moderate the interferences and upgrade the power quality and dependability. For tackling such kind of power quality issues, in writing perspective, there are a few techniques in view of power electronic devices which are utilized as a part of both transmission and conveyance systems. Another converter has been planned comprising of power electronic devices and with the assistance of anfis control, music can be removed for investigation. Among the previously mentioned FACTS devices UPFC emerges as a result of its extraordinary nature to at the same time control different parameters of the framework, for example, the transport voltage, line impedance and stage point. UPFC is viewed as noteworthy for damping power framework motions as of late.

\section{UNIFIED POWER FLOW CONTROLLER}

The UPFC (unified power flow controller) is one of the facts devices, which can uniquely control all the parameters of transmission line such as, line voltage, line impedance, phase angle and power. UPFC is a combination of two back-back converters namely series and shunt converters are separated a dc-link capacitor. Two converters exchange active and reactive powers through the dc link capacitor. The basic schematic diagram for UPFC is shown in figure 1.

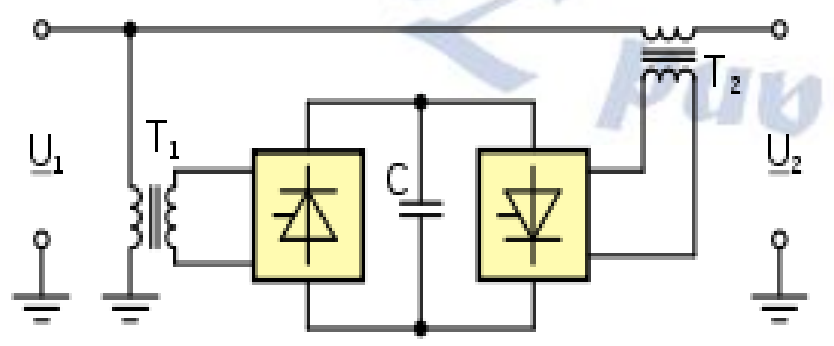

Figure 1: Schematic Construction of UPFC

The capability of unrestricted series voltage injection together with independently controllable reactive power exchange offered by the circuit structure of the two decoupled converters facilitates several operating and control modes for the UPFC. These include the option of reactive shunt compensation and the free control of series voltage injection according to a prescribed functional approach selected for power flow control. The UPFC circuit structure, also allows the total de-coupling of the two converter (i.e., separating the dc terminals of the two converters) to provide independent reactive shunt compensation (STATCOM) and reactive series compensation (SSSC) without any real power exchange.

Since, two (series \& shunt) converters of UPFC consisting of transformers in their construction which leads to aforementioned problems associated with transformers (likely high cost, bulky, lossy and slow in response). In order to meet the specifications and working conditions of the transformed upf, this paper proposes a new concept for transformerless upfc with cascaded multilevel inverter (CMI) based series converter and shunt converter. Figure 2 shows the structure of transformerless unified power flow controller.

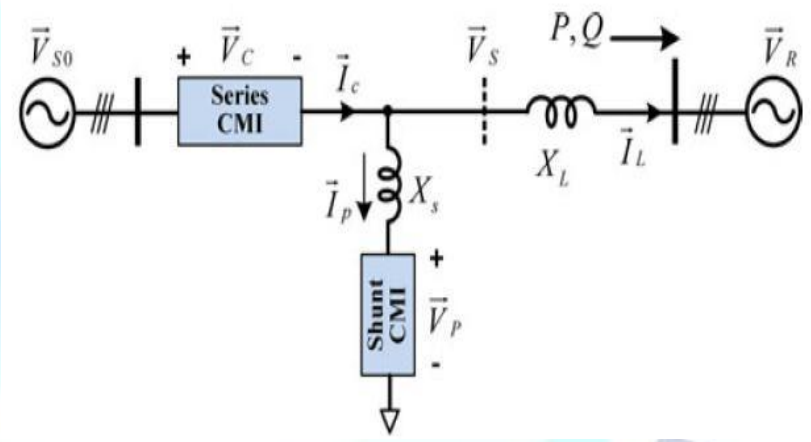

Figure 2: Structure of transformerless UPFC

\section{CONTROL STRATEGY OF UPFC}

This paper proposes a new stage of control system for UPFC for better controlling the active and reactive powers in the line and also to maintain the capacitor voltages of both $\mathrm{CMI}$ at a suitable value. The control strategy of transformerless UPFC is classified into several stages as cases:

\section{Case 1:}

Voltage and current generation for series and shunt CMI, individually. For series CMI, output voltage could be straightforwardly created from the reference $\mathrm{V}^{*} \mathrm{C}$ by $\mathrm{FFM}$. While for shunt CMI, decoupling feedback current control is utilized to control output current to take after the reference current $I^{*} \mathrm{P}$, as appeared in Figure 3.

\section{Case 2:}


Overall dc-link voltage regulation. As per the reference equations mentioned below the dc-link voltage cannot be controlled due to 1) Power loss in the CMI Converter, 2) the calculation error caused by the parameter deviations, 3) the error reference signal obtained from actual and reference signals.

$$
\begin{aligned}
& V_{C o d}^{*}=V_{S o d}-V_{S d}^{*}=V_{S o d}-\left(R_{L} I_{L d}^{*}+L_{L} \frac{d I_{L d}^{*}}{d t}-w L_{L} I_{L q}^{*}+V_{R d}\right) \\
& V_{C o q}^{*}=V_{S o q}-V_{S q}^{*}=V_{S o q}-\left(R_{L} I_{L q}^{*}+L_{L} \frac{d I_{L q}^{*}}{d t}-w L_{L} I_{L d}^{*}+V_{R q}\right)
\end{aligned}
$$

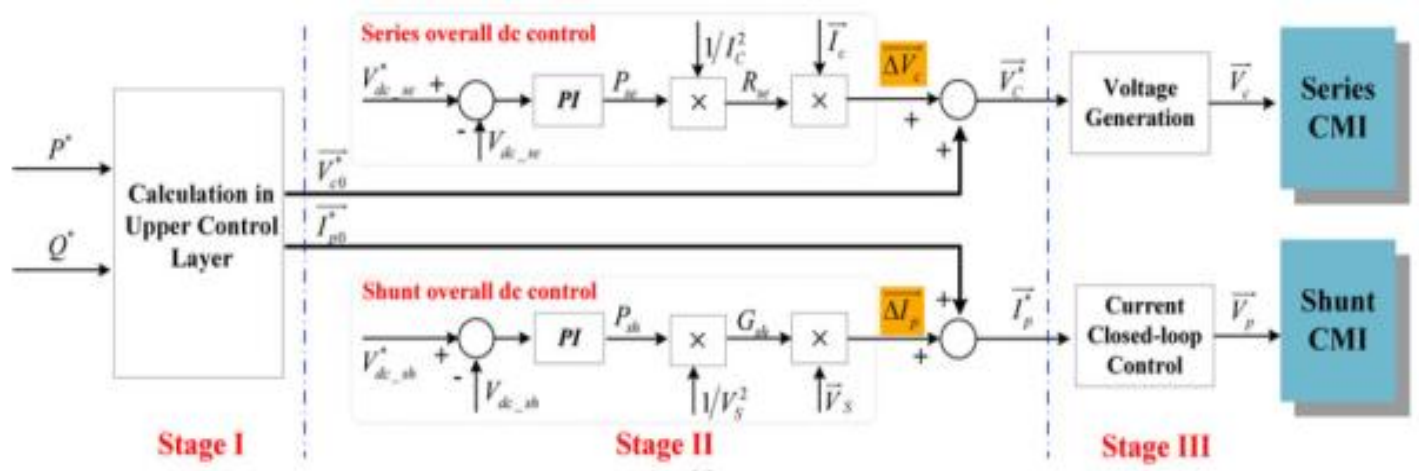

(a)

Figure 3: Transformerless UPFC Control Strategy

The mathematical model and detailed parameters design for the general dc voltage control. More often than not, the CMI ought to be

$$
P+j Q=\frac{\left(-\frac{V_{S 0} V_{R}}{X_{L}} \sin \delta_{o}\right.}{P_{O}}+\frac{\left.\frac{V_{C} V_{R}}{X_{L}} \sin \left(\delta_{o}-\delta\right)\right)}{P_{C}}+
$$

\section{ADAPTIVE NEURO-FUZZY INFERENCE SYSTEM:}

The ANFIS is one of the important controller in adaptive techniques. This section provides the information regarding the designing of neuro-fuzzy controller. These neural network controller consists of two inputs that are $\Delta \mathrm{e}$ and $\Delta$ de and it has one output that is $\mathrm{f} \in\{\Delta \mathrm{e}, \Delta \mathrm{de}\}$ [11]. Each input consists of 5 membership functions. Figure 4(a) shows the configuration of ANFIS for a mamdani type and it has two input and one output.

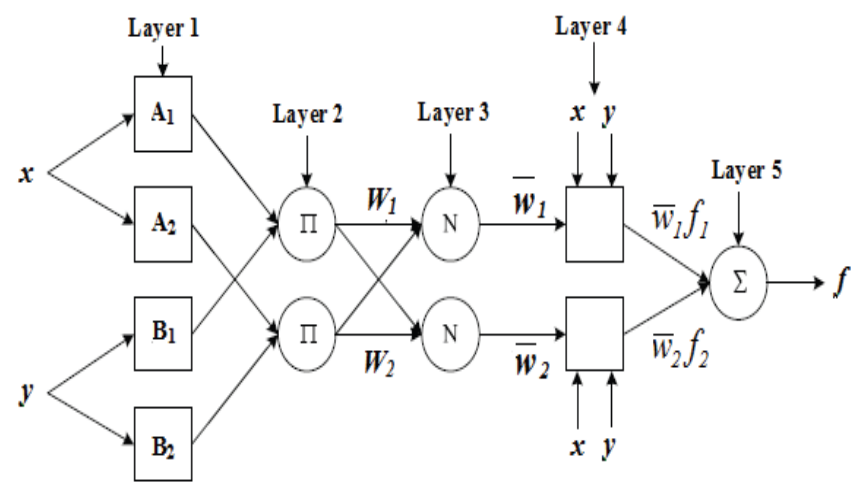

Figure 4(a): ANFIS architecture considered as three single-stage inverters, in this way, the dc capacitor voltage will contain the $2 \omega$ part. To keep the normal dc track the signals without being influenced by the $2 \omega$ distortions, the data transmission of current control and dc voltage control loop is designed to be differential.

$$
j \frac{\left(-\frac{V_{S 0} V_{R}}{X_{L}} \cos \delta_{o}-\frac{V_{R}^{2}}{X_{L}}\right.}{Q_{O}}+\frac{\left.\frac{V_{C} V_{R}}{X_{L}} \sin \left(\delta_{o}-\delta\right)\right)}{Q_{C}}
$$

According to Figure 4(b), it is a mamdani based fuzzy controller with two inputs and one output and the rules are formed according to if-then statements. $\mu \mathrm{Ai}$ and $\mu \mathrm{Bi}$ are the membership functions of memberships with the fuzzy sets and these inputs are related with the operator logical AND. The hybrid learning algorithms are implemented for obtaining the values of system parameters. These learning algorithms is a function of linear and non-linear parameters [12]. These explanations are implemented in Matlab/Simulink software.

\section{Algorithm for Neuro Controller:}

1. Assume the inputs and outputs in the normalized form with respect to their maximum values and these are in the range of 0-1.

2. Assure the No.of input stages given network.

3. Indicate the No.of hidden layers for the network.

4. Design the new feed forward network based on the system parameters 'transig' and 'poslin'.

5. Assume the learning rate be 0.02 for the given network.

6. Identify the number of iterations for the system. 
7. Enter the goal.

8. Train the network based on the given input and outputs.

9. For the given network Generate simulation with a command 'genism'

FUZZY CONTROLLER:

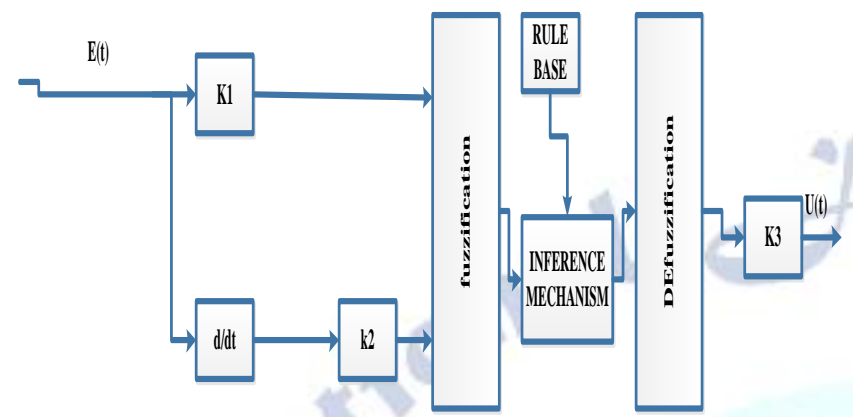

Figure 4(b): Configuration of Fuzzy Inference System

\section{SIMULATION EXPERIMENT \& RESULTS}

The simulation case study is studied and tested as per the circuit shown in figure 2 and the results for different parameters under two cases: such as PI and ANFIS controller is observed. Finally, the results are compared and verified between PI \& ANFIS controllers.

Case 1: With PI based Transformerless UPFC
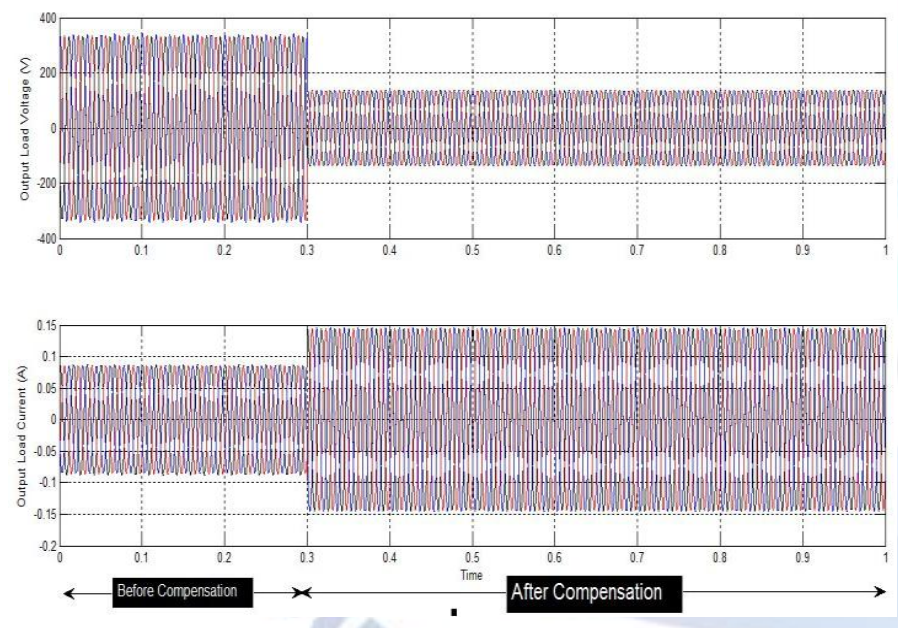

Figure 5: Simulation Results for Output Voltage \& Current using PI Controller

Figure 5, shows the simulation results for voltage and current waveforms at load side. The simulation results are shown under before and after compensation. At $\mathrm{t}=0.3 \mathrm{~s}$, upfc is connected to the system.

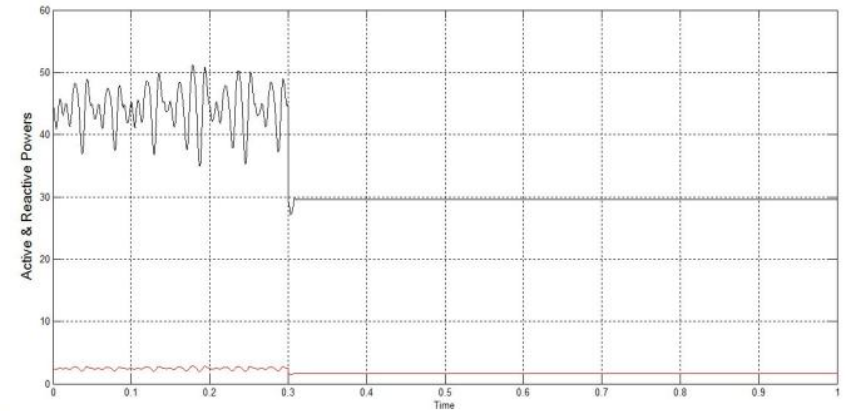

Figure 6: Simulation results for System Active and Reactive Powers

Figure 6 , shows the simulation results for active and reactive powers of the system.

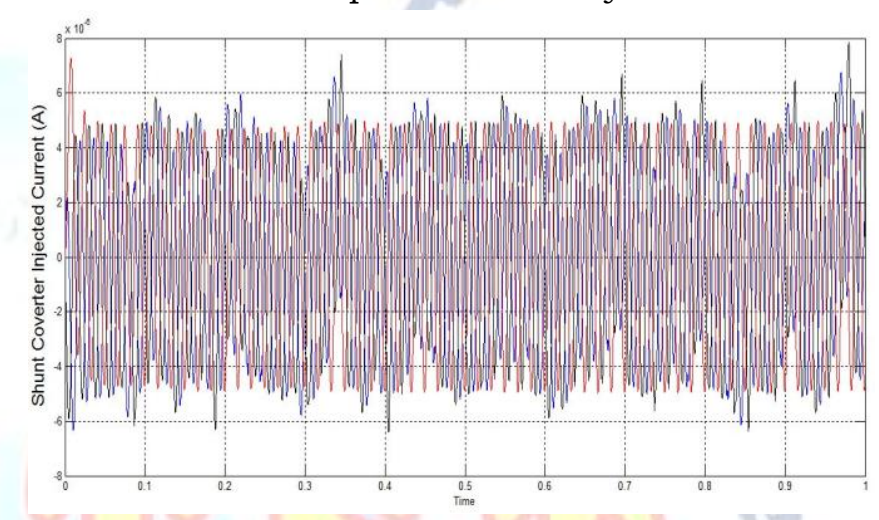

Figure 7: Simulation results for Injected Current from Shunt Converter

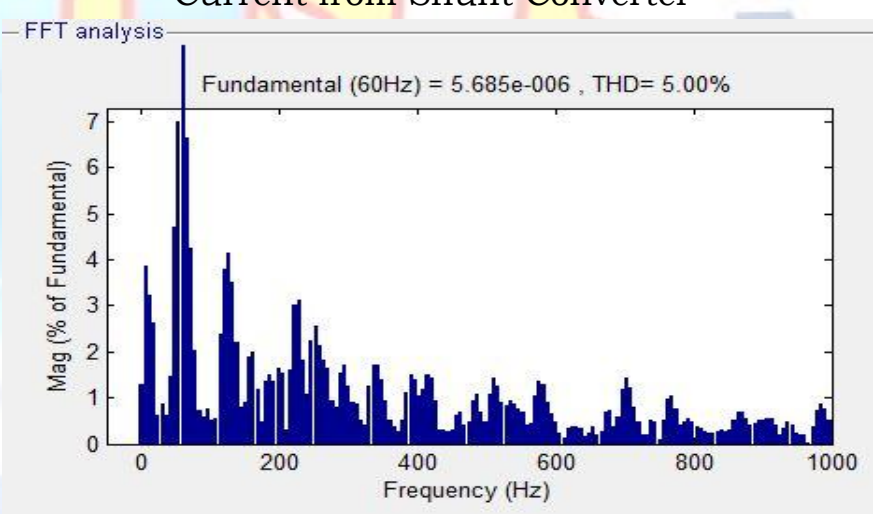

Figure 8: THD for Shunt Converter Current

Case 2: With ANFIS based Transformerless UPFC
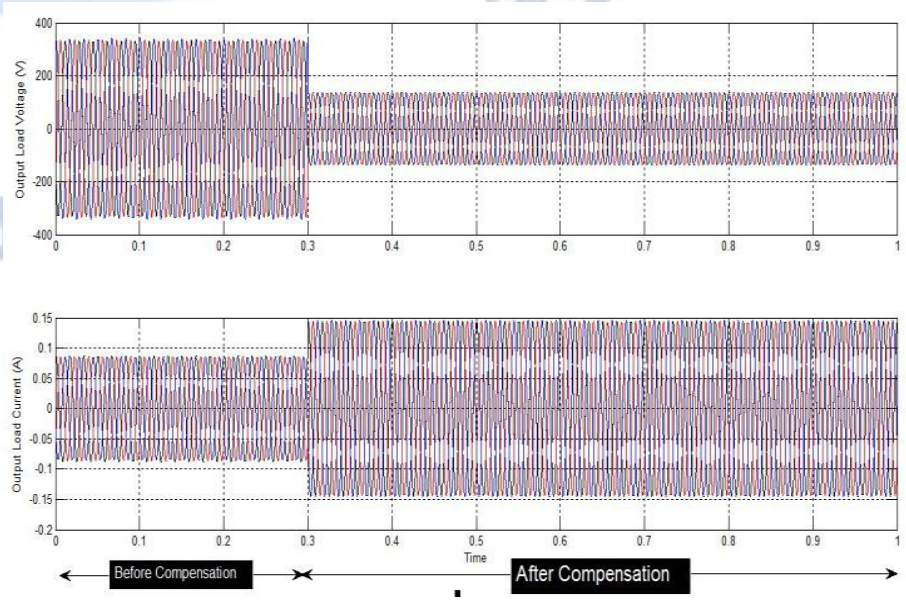
Figure 9: Simulation Results for Output Voltage \& Current using ANFIS Controller

Figure 9, shows the simulation results for voltage and current waveforms at load side. The simulation results are shown under before and after compensation. At $\mathrm{t}=0.3 \mathrm{~s}$, upfc is connected to the system.

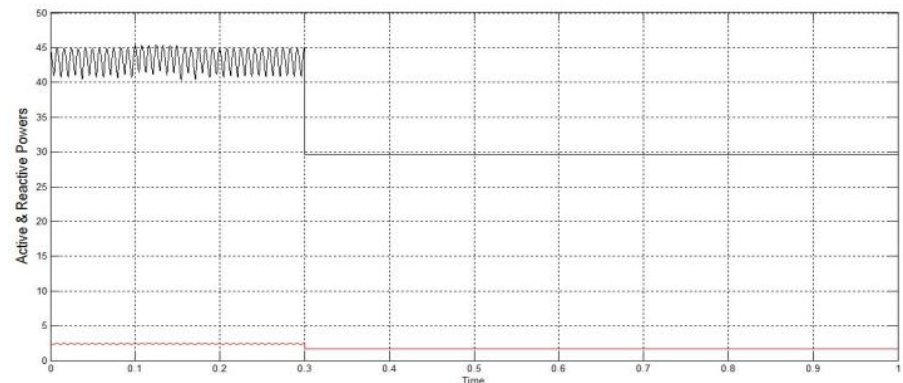

Figure 10: Simulation results for System Active and Reactive Powers

Figure 10, shows the simulation results for active and reactive powers of the system.

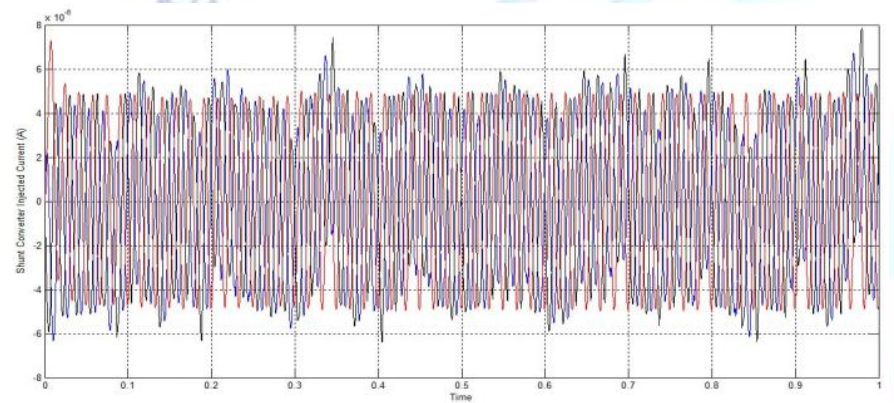

Figure 11: Simulation results for Injected Current from Shunt Converter

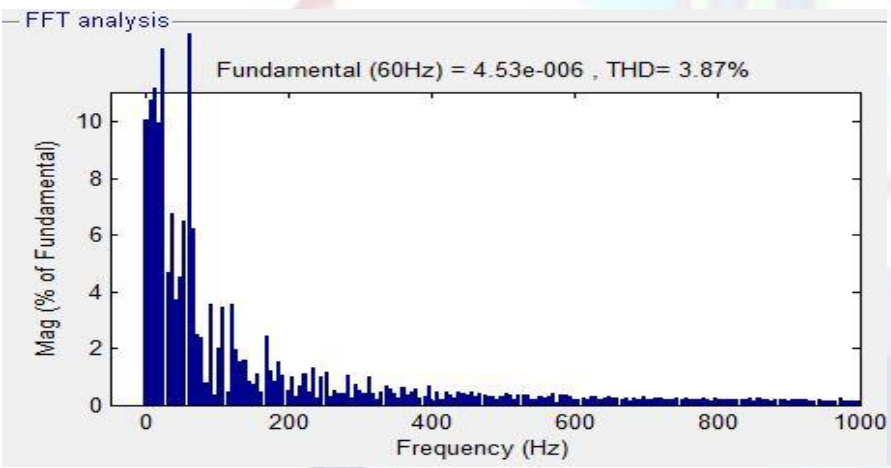

Figure 12: THD for Shunt Converter Current

From figures $8 \& 12$, we conclude that the ANFIS Controller bitterly compensate the Harmonic Distortion as compared with the conventional PI controller. The THD value with ANFIS controller is $3.87 \%$ as with PI controller THD is $5.00 \%$.

\section{CONCLUSION}

In this paper an ANFIS based transformerless upfc is proposed in order to control the active and reactive powers independently. In this UPFC series converter is designed with Cascaded multilevel inverter in order to control dc-link voltage and for better voltage level improvements. Different power control techniques has been developed mainly with PI and ANFIS controllers. When compared to PI technique the ANFIS controller is best to reduce the harmonic distortion and better voltage and current control.

\section{REFERENCES}

[1] Shuitao Yang, Yang Liu, Xiaorui Wang, presented a paper on "Modulation and Control of Transformerless UPFC" at IEEE TRANSACTIONS ON POWER ELECTRONICS, VOL. 31, NO. 2, FEBRUARY 2016.

[2] L.Gyugyi, C.D. Schauder, S. L.Williams, T. R. Rietman,D. R. Torgerson, andA. Edris, "The unified power flow controller: A new approach to power transmission control," IEEE Trans. Power Del., vol. 10, no. 2, pp. 1085- 1097, Apr. 1995.

[3] A. Rajabi-Ghahnavieh, M. Fotuhi-Firuzabad, M. Shahidehpour, and R. Feuillet, "UPFC for enhancing power system reliability," IEEE Trans. Power Del., vol. 25, no. 4, pp. 2881-2890, Oct. 2010.

[4] H. Fujita, Y. Watanabe, and H. Akagi, "Control and analysis of a unified power flow controller," IEEE Trans. Power Electron., vol. 14, no. 6, pp. 1021-1027, Nov. 1999.

[5] M. A. Sayed and T. Takeshita, "Line loss minimization in isolated substations and multiple loop distribution systems using the UPFC," IEEE Trans. Power Electron., vol. 29, no. 11, pp. 5813-5822, Jul. 2014.

[6] H. Fujita, Y. Watanable, and H. Akagi, "Transient analysis of a unified power flow controller and its application to design of dc-link capacitor," IEEE Trans. Power Electron., vol. 16, no. 5, pp. 735-740, Sep. 2001.

[7] H. Fujita, H. Akagi, and Y.Watanable, "Dynamic control and performance of a unified power flow controller for stabilizing an AC transmission system," IEEE Trans. Power Electron., vol. 21, no. 4, pp. 1013-1020, Jul. 2006.

[8] L. Liu, P. Zhu, Y. Kang, and J. Chen, "Power-flow control performance analysis of a unified power-flow controller in a novel control scheme," IEEE Trans. Power Del., vol. 22, no. 3, pp. 1613-1619, Jul. 2007.

[9] S. Kanna, S. Jayaram, and M. M. A. Salama, "Real and reactive power coordination for a unified power flowcontroller," IEEE Trans. Power Syst., vol. 19, no. 3, pp. 1454-1461, Aug. 2004.

[10] J. Z. Bebic, P. W. Lehn, and M. R. Iravani, "P- $\Delta$ characteristics for the unified power flow controller Analysis inclusive of equipment ratings and line limits," IEEE Trans. Power Del., vol. 18, no. 3, pp. 1066-1072, Jul. 2003.

[11] C. D. Schauder, L. Gyugyi, M. R. Lund, D. M. Hamai, T. R. Rietman, D. R. Torgerson, and A. Edris, "Operation of the unified power flow controller (UPFC) under practical constraints," IEEE Trans. Power Del., vol. 13, no. 2, pp. 630-639, Apr. 1998.

[12] S. Y. Kim, J. S. Yoon, B. H. Chang, and D. H. Baek, "The operation experience of KEPCO UPFC," in Proc. 8th Int. Conf. Electr. Mach. Syst., 2005, pp. 2502-2505. 